\title{
Factors Affecting Opioid Treatment in Cancer Patients
}

Matina Symeonidi, Irene Panagiotou, Efi Parpa, Eleni Tsilika, Anna Roumeliotou, Antonis Galanos, Kyriaki Mystakidou.

Pain Relief and Palliative Care Unit, Department of Radiology, Areteion Hospital, School of Medicine, National and Kapodistrian University of Athens, Greece.

Received, June 20, 2018; Revised, July 2, 2018; Accepted July 4, 2018; Published, July 10, 2018.

\begin{abstract}
Purpose: Pain is prevalent in cancer patients, appearing to be moderate to severe in more than one third of them. Despite the fact that fentanyl is widely used with effective analgesic results, some patients do not correspond to treatment, resulting in opioid change. Methods: This is a cohort study, performed in Greek patients with cancer. Its scope was to identify potential reasons responsible for opioid change, due to transdermal-fentanyl intolerance, resulting from inadequate analgesia (pain relief $<33 \%$ in 1week) and/or unacceptable adverse-events (grade $\geq 3$ at Common Terminology Criteria-v4.0). The final sample included 289 participants. To investigate responsible reasons for transdermal-fentanyl intolerance we studied its relation with patients' history, haematology, biochemistry, body-mass-index, demographic and disease related characteristics. The Eastern Cooperative Oncology Group performance status scale, the Mini Mental State Examination questionnaire, the M.D.Anderson Symptom Inventory and the Greek Brief Pain Inventory were also used to measure performance status and quality-of-life for the same reason. Results: Almost one third of the patients had to change to an alternative opioid oral-morphine in order to achieve adequate analgesia or/and avoid adverse-events. The most common adverse-events observed were nausea/vomiting and sleepiness. Statistical analysis demonstrated that younger age $(\mathrm{OR}=0.976)$ and obesity $(\mathrm{OR}=0.29$ against underweight, $\mathrm{OR}=0.39$ against normal, $\mathrm{OR}=0.48$ against pre-obese $)$ had a higher possibility to contribute to modification of the analgesic treatment. Furthermore, a higher impact of symptoms in patient's life $(\mathrm{OR}=1.184)$ and chemotherapy $(\mathrm{OR}=2.109)$ could also contribute to the need of change of the opioid analgesic medication. Conclusion: This study found significant variables for transdermal-fentanyl intolerance. This knowledge may help person-center care in moderate to severe cancer pain.
\end{abstract}

This article is open to POST-PUBLICATION REVIEW. Registered readers (see "For Readers") may comment by clicking on ABSTRACT on the issue's contents page.

\section{INTRODUCTION}

Chronic pain is a complex condition. It may appear as physical, emotional or mental pain or a combination of these and it affects the whole life of a person (1-3). Its relation to the quality of life has been studied and seems to be dependent on sleep, eating behavior, walking and relationships with other people $(4,5)$, thus proving and emphasizing the importance of correct analgesia.

Pain is prevalent in cancer. More than half of patients who have the disease at a metastatic or advanced stage and those undergoing anti-cancer treatment, are in moderate to severe pain (6). Studying the impact of pain on life and pain management, a clinical research carried out in 2007 in more than 4,000 European cancer patients showed that $73 \%$ suffered from pain at some time during their illness and half described it as moderate to severe. Further, this study maintains that pain is not effectively managed if it noticeably decreases the quality of life, and negatively affects the patient's relationship with other people despite being prescribed certain analgesic medication (7).

Fentanyl, a mu-opioid agonist is a potent opioid drug (8), recommended on the third step of the World Health Organization analgesic ladder for moderate to severe pain, and this is valid up to the present time (9-11). Its low molecular weight, high potency and lipid solubility make it suitable and valuable in handling chronic cancer pain (9). The fentanyl patch is valuable in patients who cannot swallow or remember to take their medication (8) and in patients with bowel obstruction and severe emesis (12). Transdermal therapeutic system of fentanyl (TTS-fentanyl) comes in dosages of 12, $25,50,75$ and $100 \mu \mathrm{g} / \mathrm{h}$. After the initial patch application, fentanyl release increases gradually, leveling off between 12-24 hours and continuing

Corresponding Author: Matina Symeonidi, Pain Relief and Palliative Care Unit, Department of Radiology, Areteion Hospital, School of Medicine, National and Kapodistrian University of Athens, Greece; E-mail: matina_symeonidi @ hotmail.com 
Abbreviations. TTS-fentanyl: Transdermal Therapeutic System of Fentanyl; AEs: Adverse Events; LBW: Lean Body Weight; IBW: Ideal Body Weight; BMI: Body Mass Index; ECOG: Eastern Cooperative Oncology Group; G-BPI: Greek Brief Pain Inventory MDASI: M.D.Anderson Symptom Inventory; MDASI-F1: MDASI-Factor1; MDASI-F2: MDASIFactor2 MMSE: Mini Mental State Examination; OR: Odds Ratio; CI: Confidence Interval; SD: Standard Deviation.

with almost stable concentrations up to 72 hours.

Despite the fact that fentanyl is widely used with effective analgesic results $(9,13,14)$ some patients do not respond to treatment. This is either because the desired analgesia is not being achieved even at high doses, or because of unacceptable adverse events (AEs), including vomiting, nausea, constipation, sedation, insomnia, drowsiness, diarrhoea, delirium, myoclonus and respiratory depression. For these patients the need to change opioid medication is considered essential $(9,13,15$ 18). Although it is also safe and effective as a single opioid for most of the patients (19), some have no actual relief. Other factors that were found to contribute to this issue were age (20-28), lean body weight (LBW) (29), ideal body weight (IBW) (30), renal impairment, polypharmacy, lower Karnofsky performance status $(31,32)$ and partial or total removal due to any reason like sweating (33).

The objective of the study was to investigate reasons for intolerance of TTS-fentanyl, resulting from inadequate analgesia and/or presence of unacceptable AEs in Greek cancer patients with moderate to severe pain. Patients' age, medical history, haematology, biochemistry, body-massindex (BMI), demographic and disease related characteristics were examined for possible relations with alternating opioid analgesic medication.

Novelty: This paper sets out to challenge thinking and provide useful factors that a care-giver can easily take into consideration in clinical practice to choose the most suitable analgesic medication or to alter the analgesic medication of a newly admitted patient without pain relief. We believe that the proper choice of opioid, depending on clinical examination, may provide a more effective and safe treatment for the patient. In the literature, the reasons for altering opioid analgesic medication are not quite clear and new findings are reported in this paper. The interference of symptoms with daily life, body weight, cognitive function and whether the patient is under chemotherapy or not, are an integral part of patient's life but have not been addressed in the previous work of scientists. This study focuses on these and other phenotypic characteristics and on the need for change of analgesic medication, setting out explicit evidence. Furthermore, this is the first study to recruit a sufficient number of patients from one country, thus proposing more valid results.

\section{MATERIALS AND METHODS}

\section{Study approval and patient recruitment}

This is a cohort study carried out on Greek cancer patients. Participants were recruited in the palliative care unit of the Areteion National \& Kapodistrian University Hospital of Athens, within the framework of person-centred care. Participants were from all over the country, including urban, suburban and rural areas. The inclusion criteria were: age $>18$ years, histologically confirmed malignancy, chronic intolerable cancer pain requiring strong opioid analgesics, having signed informed consent prior to any study-related activities and able to communicate effectively with the study personnel. Patients with an estimated survival of less than 3 months and patients prior to being treated with fentanyl or morphine were excluded from the study. No other opioids were used in these patients before enrolling them in the study.

Within a two-year study period (2009-2011) 1011 patients were referred to the pain relief and palliative care unit for pain and symptom control. Of these, 730 were diagnosed with cancer and 413 had moderate to severe pain. Taking into consideration the inclusion and exclusion criteria, 350 patients were found to be eligible to participate in the current study. The final sample consisted of 289 due to the refusal of some to complete the assessments, missing lab data and patients' noncompliance with treatment.

The research was approved by the Institutional Review Board of the hospital. The study was carried out in accordance with the Helsinki Declaration and according to European guidelines for good clinical practice. The informed consent of all participants was obtained before administering any medication. All patients were followed up after the completion of the study.

\section{Data Collection}

The patients' pain intensity, medical history, concomitant medication, adverse events, BMI, haematology, biochemistry, demographic and cancer-related characteristics were recorded at screening and on follow-up visits (table 1). Performance status, quality-of-life and symptom assessment questionnaires and scales were also documented. Pain intensity and possible AEs were 
recorded at baseline, on day 1, 2, 3, 7 and 14 for all patients.

The patients' performance status was assessed by the 0-4 Eastern Cooperative Oncology Group (ECOG) performance status scale (0: for a patient who was fully active-; 4: for completely disabled) (34). The ECOG was demonstrated in two categories $0-1$ and $2-3$. The pain intensity score was measured using the Greek Brief Pain Inventory (GBPI) which is an 11-point scale (score from $0-10$, with $0=$ no pain, $10=$ the worst pain ever felt) (35). BMI was in 4 categories: $<18.50$ for underweight, 18.50-24.99 for normal, 25-29.99 for overweight pre-obese and $\geq 30$ for obese (36).

Table 1. Data related to patients' categorical characteristics.

\begin{tabular}{lll}
\hline & $\mathrm{n}$ & $\%$ \\
\hline Male & 163 & 56.4 \\
Female & 126 & 43.6 \\
$\begin{array}{l}\text { Eastern Cooperative Group } \\
\text { Performance Status Score }\end{array}$ & & \\
$0-1$ & 142 & 49.1 \\
$2-3$ & 147 & 50.9 \\
Body Mass Index & & \\
Underweight & 48 & 16.6 \\
Normal & 149 & 51.6 \\
Overweight pre-obese & 62 & 21.5 \\
Obese & 30 & 10.4 \\
Comorbidities & & \\
No & 115 & 39.8 \\
Yes & 174 & 60.2 \\
Smoking & & \\
No & 163 & 56.4 \\
Yes & 126 & 43.6 \\
\hline
\end{tabular}

Heavy Drinking

No

$258 \quad 89.3$

Yes

31

10.7

Mini Mental State

Examination Test

Abnormal

55

19.0

Normal

234

81.0

Primary Cancer Location

Breast

\begin{tabular}{lll} 
& $\mathrm{n}$ & $\%$ \\
\hline Urogenital & 566.0 & 1994 \\
Prostate & 23 & 8.0 \\
Lung & 67 & 23.2 \\
Gastrointestinal & 76 & 26.3 \\
Others & 40 & 13.8
\end{tabular}

Metastasis

No

$63 \quad 21.8$

Yes

$226 \quad 78.2$

Bone Metastasis

No

$184 \quad 63.7$

Yes

$105 \quad 36.3$

Recent chemotherapy

No

$230 \quad 79.6$

Yes

$59 \quad 20.4$

Recent radiotherapy

No

$233 \quad 80.6$

Yes

$56 \quad 19.4$

Recent Bisphosphonates

No

239

82.7

Yes

17.3

Concomitant non-steroidal anti-inflammatory drugs

No

$212 \quad 73.4$

Yes

$77 \quad 26.6$

Concomitant

Dexamethasone

No

$97 \quad 33.6$

Yes

192

66.4

Concomitant

Antidepressants

No

$173 \quad 59.9$

Yes

$116 \quad 40.1$

Concomitant

Anticonvulsants

$\begin{array}{lll}\text { No } & 100 . & 34.6\end{array}$

$\begin{array}{lll}\text { Yes } & 189 & 65.4\end{array}$

Prior Non-opioid Analgesic

No

$131 \quad 45.3$

Yes

$158 \quad 54.7$ 
Table 2. Data related to continuous characteristics.

\begin{tabular}{|c|c|c|c|c|}
\hline & Mean & SD & Min & Max \\
\hline Age (years) & 66.1 & $\begin{array}{l}12 . \\
0\end{array}$ & 28.0 & 98.0 \\
\hline M.D. Anderson Symptom Inventory-Factor 1 & 3.6 & 1.9 & 0.1 & 7.9 \\
\hline M.D. Anderson Symptom Inventory-Factor 2 & 5.6 & 3.3 & 0.0 & 10.0 \\
\hline Haematocrit (\%) & 36.3 & 5.7 & 19.9 & 52.0 \\
\hline Hemoglobin (gr/dl) & 11.9 & 2.0 & 5.8 & 17.7 \\
\hline White Blood Cells $(\mathrm{K} / \mu \mathrm{l})$ & 9.3 & 6.4 & 2.0 & 41.9 \\
\hline Lymphocytes (\%) & 20.2 & $\begin{array}{l}11 . \\
4\end{array}$ & 3.0 & 67.0 \\
\hline Blood Urea (mg/dl) & 46.8 & $\begin{array}{l}24 . \\
6\end{array}$ & 5.0 & 136 \\
\hline Creatinine $(\mathrm{mg} / \mathrm{dl})$ & 1.1 & 0.5 & 0.4 & 4.0 \\
\hline$\gamma$-Glutamyl Transferase (IU/l) & 117.5 & $\begin{array}{l}21 \\
4.0\end{array}$ & 9.0 & 1556 \\
\hline Alkaline Phosphatase (IU/l) & 273.8 & $\begin{array}{l}44 \\
7\end{array}$ & 19.0 & 2695 \\
\hline Total Proteins $(\mathrm{g} / \mathrm{dl})$ & 6.8 & 1.0 & 4.1 & 8.6 \\
\hline Albumin $(\mathrm{g} / \mathrm{dl})$ & 4.0 & 1.0 & 2.3 & 7.1 \\
\hline
\end{tabular}

The symptoms severity and its interference in daily life were measured via the M.D. Anderson Symptom Inventory (MDASI) (37), which consists of 19 questions (13 symptom severity items and 6 symptom interference items). MDASI is an 11-point scale questionnaire (0-10, 0 : for no symptom present and 10: as bad as the patient can imagine), validated also in Greek cancer patients (38). The mean score of the MDASI symptom severity items was indicated via MDASI-Factor1 (MDASI-F1) and the mean score of symptom interference items with MDASI-Factor2 (MDASI-F2).

The mental state was measured using the 30-point Mini Mental State Examination (MMSE) questionnaire test valid in Greek cancer patients. Any score $\geq 24$ points (out of 30 ) indicated a normal cognition (39).

Finally, comorbidities recorded were dyslipidemia, diabetes mellitus, spinal degenerative disease, hypertension or coronary artery disease, thyroid dysfunction, diverticulitis and the existence of intestinal polyps. Any significant amount of alcohol intake was also documented via heavy drinking as defined by the literature (40).

\section{Patients' Treatment}

All patients received TTS-fentanyl at the beginning of the study with initial doses of 12 or $25 \mu \mathrm{g} / \mathrm{h}$. Patches used were: TTS Durogesic, Janssen-Cilag Pharmaceutical S.A.C.I., Athens, Greece; TTS Fentadur, Lavipharm S.A., Athens, Greece; TTS
Matrifen, Takeda Hellas S.A., Athens, Greece. The dose of TTS-fentanyl was titrated until the desirable analgesia was achieved (a pain score of equal to or less than $33 \%$ of pain at baseline on the analogue scale of G-BPI in the first week). Dose increments were of 12 or $25 \mu \mathrm{g} / \mathrm{h}$ according to the patient's individual need for pain relief and were not made at intervals of less than 48 hours, although the first increase was at 72 hours.

Additional medications, including adjuvant analgesics, were used in all patients so as to diminish the possibility of ineffectiveness of the opioid (41). Steroidal and non-steroidal anti-inflammatory drugs, antidepressants and anticonvulsants were used for this reason. Supportive care was used for all cancer symptoms or for a patient's concomitant diseases and for AEs caused by the main opioid medication. Subjects who experienced unacceptable AEs or cases where the desirable analgesia was not achieved within one week, were prescribed oral-morphine. Titration of morphine also achieved pain relief. Doses of morphine were given according to known conversion ratios between the two opioids $(42,43)$. Oralmorphine was considered a successful choice when the pain score was equal to or less than $33 \%$ of pain at the time of change within 7 days $(42,43)$. None of the adjuvant analgesics was changed during the study, not even after the change from TTS-fentanyl to oral morphine, so as to avoid misinterpretation from drugdrug interactions. 
All patients were requested to contact us if the patch lifted off the skin due to sweating or for other reasons. None of the patients was to take any analgesic or adjuvant analgesic medication other than those prescribed by the study team.

\section{Adverse Events}

Vomiting, nausea, constipation, sedation and respiratory depression seem to be the most frequently occurring AEs in opioids according to literature $(9,13,15-18)$. In the present study, constipation, nausea, vomiting, sleep disturbance, diarrhoea, dizziness, pruritus/rash, sweating, dry mouth, respiratory depression, and confusion were documented. Grading was performed using Common Terminology Criteria for Adverse Events version 4.0 (reference). A grade $\geq 3$, even after the use of adjuvant, was considered unacceptable and, so the analgesic treatment had to be changed.

\section{STATISTICS}

Correlations between patients' data and opioid change were investigated by univariate and multivariate regression analyses. For the univariate analysis of categorical characteristics, the Chi-Square test was used. For continuous characteristics (Table 2 and )the univariate analysis (Table 3 ) of patients, the Student's t-test was used. The resulting statistically significant factors were used in a multiple logistic regression analysis using the Backward elimination Wald method to demonstrate the odds ratio (OR). The probability value $\mathrm{p}<0.05$ was considered statistically significant.

\section{RESULTS}

The 289 participants (163 males, 126 females) had a mean age of 66.1 years. Tables 1 and 2 demonstrate the characteristics of the final sample. The recorded means of MDASI were for symptom severity items between 0.1-7.9 and for symptom interference items between 0.0-10.0 (table2). Mean score of pain at baseline was $7.5( \pm \mathrm{SD}=2.0)$ with minimum pain score 5.0 and maximum 10.0 at G-BPI (Figure1).

Almost $1 / 3$ of the patients had to switch to morphine in order to achieve adequate analgesia and/or avoid AEs: 50 (58\%) changed because of inadequate analgesia despite of dose increase, 16 (19\%) due to AEs $\geq$ grade 3 and $20(23 \%)$ due to both poor analgesia and AEs. The most common AEs $\geq$ grade 3 observed in this study were nausea/vomiting $(33.3 \%)$, sleepiness $(30.6 \%)$ and respiratory depression $(27.8 \%)$.

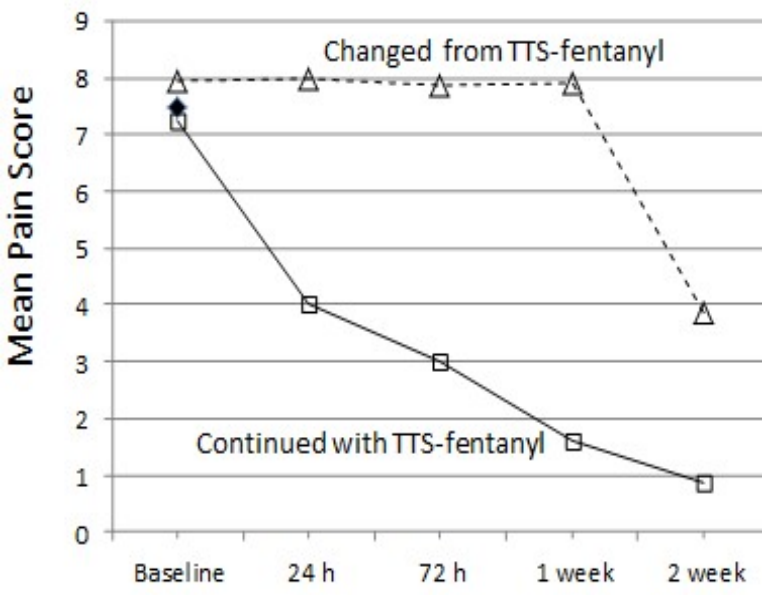

Figure 1. Mean of pain scores of 289 participants at baseline ( $\bullet$ and subsequent assessments in patients who continued with TTS-fentanyl $(\mathrm{n}=203)$ and those who changed to other analgesics $(\mathrm{n}=86)$.

In univariate statistical analysis a small but notable probability to change opioid treatment was found in its association with ECOG and obesity. A significant statistical association $(p<0.05)$ was found between opioid change and MMSE, concomitant chemotherapy, age, MDASI-F1 and MDASI-F2 (tables 3 and 4). There was no statistical significance between opioid change and gender, medical history, type of cancer.

Multiple logistic regression analysis (Table 5) showed that it was less likely to alter opioid medication from TTS-fentanyl to oral-morphine as age advances. Thus, the probability of change was $2.4 \%$ less in older patients $(\mathrm{OR}=0.98)$. The probability of change in patients with higher MDASI-F2 was $18.4 \%(\mathrm{OR}=1.18)$. The probability in patients recently receiving chemotherapy was 2.1 times more $(\mathrm{OR}=2.11)$ compared to those without chemotherapy. Concerning BMI, the probability indicated that the underweight patients were $74.1 \%$ less likely to change $(\mathrm{OR}=0.26)$, those with normal BMI were $65.3 \%$ less likely to change $(\mathrm{OR}=0.35)$ and the overweight but pre-obese were $54.6 \%$ less likely to change compared to obesity $(\mathrm{OR}=0.45)$. Finally, ECOG, MDASI-F1 and MMSE did not appear to be contributing factors for opioid change. The confidence interval (CI) in analyses was considered $95 \%$. 
Table 3. Univariate analysis: Association between patients' categorical characteristics and the need for alternative opioid.

\begin{tabular}{|c|c|c|c|c|}
\hline \multirow{4}{*}{ Sex } & \multirow[b]{4}{*}{ Female } & \multicolumn{2}{|l|}{ Opioid Change } & \multirow[b]{2}{*}{$p$} \\
\hline & & $\begin{array}{l}\text { No } \\
n=203.0(70.2 \%)\end{array}$ & $\begin{array}{l}\text { Yes } \\
\mathrm{n}=86.0(29.8 \%)\end{array}$ & \\
\hline & & $110(67.5)$ & $53(32.5)$ & \multirow{2}{*}{0.299} \\
\hline & & $93(73.8)$ & $33(26.2)$ & \\
\hline \multirow{3}{*}{$\begin{array}{l}\text { Eastern Cooperative Group } \\
\text { Performance Status Score }\end{array}$} & $0-1$ & $106(74.6)$ & $36(25.4)$ & \multirow{2}{*}{0.123} \\
\hline & $2-3$ & $97(66)$ & $50(34)$ & \\
\hline & Underweight & $36(75)$ & $12(25)$ & \multirow{4}{*}{0.186} \\
\hline \multirow{3}{*}{ Body Mass Index } & Normal & $107(71.8)$ & $42(28.2)$ & \\
\hline & Overweight pre-ob & $44(71)$ & $18(29)$ & \\
\hline & Obese & $16(53.3)$ & $14(46.7)$ & \\
\hline \multirow{2}{*}{ Medical History } & No & $77(67)$ & $38(33)$ & \multirow{2}{*}{0.358} \\
\hline & Yes & $126(72.4)$ & $48(27.6)$ & \\
\hline \multirow{2}{*}{ Smoking } & No & $121(74.7)$ & $42(25.8)$ & \multirow{2}{*}{094} \\
\hline & Yes & $82(65.1)$ & $44(34.9)$ & \\
\hline \multirow{2}{*}{ Heavy Drinking } & No & $182(70.5)$ & $76(29.5)$ & \multirow{2}{*}{0.836} \\
\hline & Yes & $21(67.7)$ & $10(32.3)$ & \\
\hline \multirow{6}{*}{ Primary Cancer Location } & Breast & $19(70.4)$ & $8(29.6)$ & \multirow{6}{*}{0.226} \\
\hline & Urogenital & $36(64.3)$ & $20(35.7)$ & \\
\hline & Prostate & $18(78.3)$ & $5(21.7)$ & \\
\hline & Lung & $41(61.2)$ & $26(38.8)$ & \\
\hline & Gastrointestinal & $57(75)$ & $19(25)$ & \\
\hline & Other & $32(80)$ & $8(20)$ & \\
\hline \multirow{2}{*}{ Metastasis } & No & $50(79.4)$ & $13(20.6)$ & \multirow{2}{*}{087} \\
\hline & Yes & $153(67.7)$ & $73(32.3)$ & \\
\hline \multirow{2}{*}{ Bone Metastasis } & No & $132(71.7)$ & $52(28.3)$ & \multirow{2}{*}{0.504} \\
\hline & Yes & $71(67.6)$ & $34(32.4)$ & \\
\hline \multirow{2}{*}{ Mini Mental State Examination test } & Abnormal (score $<2$ & $30(54.5)$ & $25(45.5)$ & \multirow{2}{*}{008} \\
\hline & Normal (score $\geq 24$ ) & $173(73.9)$ & $61(26.1)$ & \\
\hline \multirow{2}{*}{ Recent Chemotherapy } & No & $169(73.5)$ & $61(26.5)$ & \multirow{2}{*}{025} \\
\hline & Yes & $34(57.6)$ & $25(42.4)$ & \\
\hline \multirow{2}{*}{ Recent Radiotherapy } & No & $166(71.2)$ & $67(28.8)$ & \multirow{2}{*}{0.515} \\
\hline & Yes & $37(66.1)$ & $19(33.9)$ & \\
\hline \multirow{2}{*}{ Prior Non-opioid } & No & $96(73.3)$ & $35(26.7)$ & \multirow{2}{*}{0.366} \\
\hline & Yes & $107(67.7)$ & $51(32.3)$ & \\
\hline
\end{tabular}


Table 4. Univariate analysis: Association between patients' continuous characteristics and the need for alternative opioid.

\begin{tabular}{|c|c|c|c|}
\hline & \multicolumn{2}{|c|}{ Opioid change } & \multirow[b]{2}{*}{$p$} \\
\hline & $\begin{array}{l}\text { No } \\
(n=203)\end{array}$ & $\begin{array}{l}\text { Yes } \\
(n=86)\end{array}$ & \\
\hline Age (years) & Mean \pm SD & Mean \pm SD & 041 \\
\hline M.D. Anderson Symptom Inventory -Factor 1 & $3.3 \pm 1.9$ & $4.2 \pm 1.7$ & $<001$ \\
\hline M.D. Anderson Symptom Inventory -Factor 2 & $5.1 \pm 3.4$ & $6.7 \pm 2.7$ & $<001$ \\
\hline Haematocrit (\%) & $36.5 \pm 5.8$ & $35.9 \pm 5.5$ & 0.428 \\
\hline Haemoglobin (gr/dl) & $11.9 \pm 2$ & $11.8 \pm 1.9$ & 0.806 \\
\hline White blood cell count $(\mathrm{K} / \mu \mathrm{l})$ & $9.6 \pm 6.4$ & $8.7 \pm 8.7$ & 0.305 \\
\hline Lymphocytes (\%) & $21.2 \pm 11.8$ & $18.1 \pm 10.2$ & 035 \\
\hline Blood Urea (mg/dl) & $47.2 \pm 24.7$ & $45.9 \pm 24.5$ & 0.694 \\
\hline Creatinine (mg/dl) & $1.1 \pm 0.5$ & $1.1 \pm 0.6$ & 0.420 \\
\hline$\gamma$-glutamyltransferase (IU/l) & $112.9 \pm 210.6$ & $129.5 \pm 223.9$ & 0.584 \\
\hline Alkaline phosphatase (IU/l) & $285.9 \pm 466$ & $241.9 \pm 392$ & 0.490 \\
\hline Total proteins $(\mathrm{gr} / \mathrm{dl})$ & $6.8 \pm 1$ & $6.8 \pm 0.9$ & 0.501 \\
\hline Albumin (gr/dl) & $3.9 \pm 0.7$ & $3.9 \pm 0.7$ & 0.800 \\
\hline
\end{tabular}

\section{DISCUSSION}

Alternating opioid therapy is stated as the most effective way to treat patients with opioids (17). The reasons for this need are not to be contributing factors for opioid change are not quite clear. In this study, 86 of the 289 selected participants had to change their TTS-fentanyl analgesic medication so as to achieve adequate pain relief or even avoid AEs. The patient's medical history, cancer diagnosis, treatment, haematology, biochemistry, BMI and demographic related characteristics were studied as possible reasons for opioid change. factors found to be responsible are discussed below.

Results from univariate analysis indicated that age was associated with the opioid change. Multivariate analysis showed that every year of age might prevent altering of opioid medication from TTS-fentanyl to oral morphine. In the opposite case, a previous study correlated the change from oralmorphine to alternative opioid in ages $>78$ years (21). Many studies support the influence of age in fentanyl effectiveness. Some of them have shown reduced renal clearance and prolonged terminal elimination half-life of fentanyl and morphine administered intravenously and orally in the elderly comparing with younger ages $(22,23)$. In the findings of Holdsworth MT et al, it seemed that there was increased absorption and decreased clearance of TTS-fentanyl in the elderly (24). In a later study, TTS-fentanyl's half life was found to be increased in the elderly (25). Many other studies found differences in the pharmacokinetics and pharmacodynamics of fentanyl and morphine between younger and older patients, which offer inculpatory evidence for the variation in opioid tolerance between age groups. As a result, an inverse ratio of fentanyl dose to age was suggested (26). Furthermore, a rapid dose escalation and opioid tolerance development in younger age were indicated (27). Differences in the pharmacodynamic properties of fentanyl were also explained by decreased brain sensitivity in the aged group as determined by electroencephalographic changes (28). Moreover, differences in the perception and response to pain were noted with aging (29). On the other hand, there are studies that have found no influence of age in opioid change or opioid dose escalation $(18,43)$.

Symptom interference with daily life was strongly correlated with opioid change as shown in the univariate analysis. Symptom interference with daily life was also noted as an aggravating factor of opioid change after the multivariate analysis. MDASI-Symptom severity was found to be statistically significant only in the univariate analysis. To the best of our knowledge, previous studies did not focus on symptom distress and how symptoms interfere in patients' daily lives, as a possible reason for opioid change, and symptom questionnaires were used simply to indicate the effectiveness of switching (18). However, a 
similarity to the present study lies in the fact that there was always the need for alternative opioid after the increase of symptom severity and impact on daily life.

Statistical analysis of this study indicated a strong association between opioid change and chemotherapy. In the univariate analysis patients receiving chemotherapy were more likely to change. Similarly, multivariate analysis showed that these patients were twice as likely to change opioid treatment than those without chemotherapy. In the literature, studies have indicated that chemotherapy and chemoradiotherapy raised symptom burden, thus resulting in higher symptom severity and interference in daily life scores, with fatigue, distress and sadness as the strongest predictors of symptom interference $(44,45)$. This is consistent with the present study, as higher symptom interference was found as a reason for the need of opioid change.

In the present study univariate analysis gave rise to a suspicion of correlation between obese patients and opioid change. This was tested in multivariate analysis and a higher probability was discovered in obese patients. In the literature, there is still no clear evidence to explain this finding. What is known is that obese subjects have both an increased amount of fat- and LBW. It has been argued that clearance of fentanyl is affected by obesity, is significantly higher in obese patients and that fentanyl dosing should be based on LBW, as administration according to total body weight may lead to an overdose in the obese (30). On the other hand, oral morphine seems not to be affected by obesity (46). As fentanyl is lipophilic, obesity should affect its pharmacokinetic profiles, while a high amount of adipose tissue could result in a prolonged beta half life. On the other hand, it has been found that the pharmacokinetics of the fentanyl patch were not affected by obesity and thus suggested that fentanyl should be administered using IBW (31). In another study, absorption of TTS-fentanyl was found to be decreased in cachectic patients (47). However, in this study there was no influence of abnormal low BMI comparing to opioid change.

In the current study lower scores in cognitive function showed statistical significance for opioid change. This might stem from the fact that the higher the burden of the disease, the more possible the patients are to change their TTS-fentanyl medication. Cognitive functioning was also a factor not tested in other studies and was used simply to indicate a switching effectiveness (16). Nevertheless, this is in agreement with the present study, as the opioid change was performed in the event of a worsening of the cognitive state. In any way, fentanyl and morphine are both admitted to contribute to opioid neurotoxicity in the form of cognitive dysfunction or delirium which, among others, can be more noticeable in patients with renal impairment, polypharmacy and lower Karnofsky performance status $(32,33)$. It was suggested that this could be avoided by dose reduction or by changing route or switching to another opioid (32).

\section{Limitations, advantages and future thoughts}

The time- period in recruiting an appropriate sample size to detect a significant statistic was the limitation of this study. However, this was the first study to recruit such a number of cancer patients from one country, thus proposing more valid results. Contradictory outcomes were presented among previous studies concerning age and weight, probably due to the low number of patients. The additional finding of a positive relationship between opioid change, high symptom interference in daily living and cognitive function in this study, established a new feature that needs to be further investigated.

Recent studies connect the differentiation of opioid therapeutic response from person to person with genetic variations by means of single nucleotide polymorphisms (SNPs). A European study carried out in 2011 recruited only 5 Greek cancer patients and was thus excluded from the study (48). Genetics may provide us with answers for correct medication that could avoid patient suffering, waiting for appropriate pain and symptom management. It would be magnificent if patient treatment could be decided following the results of just a blood sample. In this study we focused on the phenotype of the patients, the observed characteristics, which at the moment are what is clinically important and this is also how genetics and epigenetics are expressed. Another paper concerning the genetical characteristics of our study-population is on statistical process and is to be published later on.

\section{CONCLUSION}

This cohort study with Greek cancer patients indicated that younger people, those with higher severity and impact of cancer-related symptoms in a patient's life, those with recent chemotherapy and those with higher BMI appeared to have a stronger probability to change opioid medication from TTSfentanyl to oral-morphine. This knowledge may help clinicians to identify at an early stage patients at specific risk to change opioid and probably provide a better treatment option. Proper choice of 
opioid depending on clinical examination may provide a more effective and safe treatment for the patient.

\section{CONFLICT OF INTEREST}

None of the authors have any conflict of interest pertaining to the contents of this article.

\section{REFERENCES}

1. Niv D, Kreitler S. Pain and quality of life. Pain Pract, 2001; 1:150-161. DOI: 10.1046/j.15332500.20011016.x.

2. Penny KI, Purves AM, Smith BH, et al. Relationship between the chronic pain grade and measures of physical, social and psychological well-being. Pain, 1999; 79:275-9. DOI: 10.1016/S03043959(98)00166-3.

3. Smith BH, Elliott AM, Chambers WA, et al. The impact of chronic pain in the community. Fam Pract, 2001; 18:292-9. DOI: 10.1093/fampra/18.3.292.

4. Mystakidou K, Parpa E, Tsilika E, et al. The relationship of subjective sleep quality, pain, and quality of life in advanced cancer patients. Sleep, 2007; 30:737-42. DOI: 10.1093/sleep/30.6.737.

5. Gerrits MM, Oppen PV, van Marwijk HW, et al. Pain and the onset of depressive and anxiety disorders. Pain, 2014; 155:53-9. DOI: 10.1016/j.pain.2013905.

6. Van den Beuken-van Everdingen MHJ, De Rijke JM, Kessels AG, et al. Prevalence of pain in patients with cancer: a systematic review of the past 40 years. Ann Oncol, 2007; 18:1437-49. DOI: 10.1093/annonc/mdm056.

7. European Pain in Cancer Survey, European Association of Palliative Care. Half of European cancer patients have moderate to severe pain: one in five patients does not receive treatment. J Pain Palliat Care Pharmacother, 2007; 21:51-3. DOI: 10.1300/J354v21n04_11.

8. Muijsers RB, Wagstaff AJ. Transdermal fentanyl: an updated review of its pharmacological properties and therapeutic efficacy in chronic cancer pain control. Drugs, 2001; 61:2289-307. DOI: 10.2165/00003495200161150-00014.

9. Gourlay GK. Treatment of cancer pain with transdermal fentanyl. Lancet Oncol, 2001; 2:165-72. DOI: $10.1016 /$ S1470-2045(00)00258-8.

10. World Health Organization. 1987. Traitement de la douleur cancéreuse. Geneva, Switz. Available from: http://whqlibdoc.who.int/publications/9242544825.pd f. Accessed 5 April, 2013.

11. Vargas-Schaffer G. Is the WHO analgesic ladder still valid? Twenty-four years of experience. Can Fam Physician, 2010; 56:514-7. http://www.cfp.ca/

12. Mercadante S, Fulfaro F. Alternatives to oral opioids for cancer pain. Oncology 1999; 13:215-20. http://www.cancernetwork.com/oncology-table-ofcontents

13. Jeal W, Benfield P. Transdermal fentanyl. A review of its pharmacological properties and therapeutic efficacy in pain control. Drugs, 1997; 53:109-38. DOI: 10.2165/00003495-199753010-00011.

14. Miyazaki T, Hanaoka K, Namiki A, et al. Efficacy, safety and pharmacokinetic study of a novel fentanylcontaining matrix transdermal patch system in Japanese patients with cancer pain. Clin Drug Investig, 2008; 28:313-25. DOI: 10.2165/00044011200828050-00005.

15. Ahmedzai S, Brooks D. Transdermal fentanyl versus sustained-release oral morphine in cancer pain: preference, efficacy, and quality of life. The TTSFentanyl Comparative Trial Group. J Pain Symptom Manage, 1997; 13:254-61. DOI: 10.1016/S08853924(97)00082-1.

16. Benítez-Rosario MA, Feria M, Salinas-Martín A, et al. Opioid switching from transdermal fentanyl to oral methadone in patients with cancer pain. Cancer, 2004; 101:2866-73. DOI: 10.1002/cncr.20712.

17. Dale O, Moksnes K, Kaasa S. European Palliative Care Research Collaborative pain guidelines: opioid switching to improve analgesia or reduce side effects. A systematic review. Palliat Med, 2011; 25:494-503. DOI: $10.1177 / 0269216310384902$.

18. Mercadante S, Ferrera P, Villari P, et al. Frequency, Indications, Outcomes, and Predictive Factors of Opioid Switching in an Acute Palliative Care Unit. J Pain Symptom Manage, 2009; 37:632-41. DOI: 10.1016/j.jpainsymman.2007.1224.

19. Mystakidou K, Befon S, Tsilika E, et al. Use of TTSfentanyl as a single opioid for cancer pain relief: a safety and efficacy clinical trial in patients naive to mild or strong opioids. Oncology, 2002; 62:9-16. DOI: 10.1159/000048241.

20. Riley J, Ross JR, Rutter D, et al. A retrospective study of the association between haematological and biochemical parameters and morphine intolerance in patients with cancer pain. Palliat Med, 2004; 18:19-24. DOI: 10.1191/0269216304pm856oa.

21. Bentley JB, Borel JD, Nenad RE Jr, et al. Age and fentanyl pharmacokinetics. Anesth Analg, 1982; 61:968-71. DOI: 10.1213/00000539-19821200000002.

22. Baillie SP, Bateman DN., Coates PE et al. Age and the Pharmacokinetics of Morphine; Age and Ageing, 1989; 18:258-62; DOI: 10.1093/ageing/18.4.258.

23. Holdsworth MT, Forman WB, Killilea TA, et al. Transdermal fentanyl disposition in elderly subjects. Gerontology, 1994; 40:32-7. DOI: $10.1159 / 000213572$.

24. Thompson JP, Bower S, Liddle AM, et al. Perioperative pharmacokinetics of transdermal fentanyl in elderly and young adult patients. Br. J. Anaesth, 1998; 81:152-154. DOI: 10.1093/bja/81.2.152.

25. Hall S, Gallagher RM, Gracely E, et al. The terminal cancer patient: Effects of age, gender, and primary tumor site on opioid dose. Pain Med, 2003; 4:125-134. DOI: 10.1046/j.1526-4637.20033020.x.

26. Buntin-Mushock C, Phillip L, Moriyama K, et al. Agedependent opioid escalation in chronic pain patients. Anesth Analg, 2005; 100:1740-5. DOI: 10.1213/01.ANE000152191.29311.9B. 
27. Scott JC, Stanski DR. Decreased fentanyl and alfentanil dose requirements with age. A simultaneous pharmacokinetic and pharmacodynamic evaluation. $\mathbf{J}$ Pharmacol Exp Ther, 1987; 240:159-66.

28. http://jpet.aspetjournals.org/Gibson SJ, Helme RD. Age-related differences in pain perception and report. Clin Geriatr Med, 2001; 17:433-56. DOI: 10.1016/S0749-0690(05)70079-3.

29. Ingrande J Lemmens HJM. Dose adjustment of anaesthetics in the morbidly obese. BJA, 2010; 105:i16-i23. DOI: 10.1093/bja/aeq312.

30. Baerdemaeker, Mortier EP, Strys MMRF. Pharmacokinetics in obese patients. Contin Educ Anaesth Crit Care Pain, 2004; 4:152-5. DOI: 10.1093/bjaceaccp/mkh042.

31. Lawlor PG. The panorama of opioid-related cognitive dysfunction in patients with cancer: a critical literature appraisal. Cancer, 2002; 94:1836-53. DOI: 10.1002/cncr.10389.

32. Kurita GP, Sjøgren P, Ekholm O, et al. Prevalence and predictors of cognitive dysfunction in opioid-treated patients with cancer: a multinational study. J Clin Oncol, 2011; 29:1297-303. DOI: 10.1200/JCO.2010.32.6884.

33. Baik SW, Kim KH, Kim YC, et al. Initial dose cascade of TTS fentanyl with proper adjuvant medications in cancer pain. J Korean Med Sci, 2003; 18:733-7. DOI: 10.3346/jkms.2003.18.5.733.

34. Oken MM, Creech RH, Tormey DC, et al. Toxicity and response criteria of the Eastern Cooperative Oncology Group. Am J Clin Oncol, 1982; 5:649-55. DOI: 10.1097/00000421-198212000-00014.

35. Mystakidou K, Mendoza T, Tsilika E, et al. Greek Brief Pain Inventory: Validation and Utility in Cancer Pain. Oncology, 2001; 60:35-42. DOI: 10.1159/000055294.

36. WHO Expert Consultation. Appropriate body-mass index for Asian populations and its implications for policy and intervention strategies. Lancet, 2004; 363:157-63. DOI: 10.1007/s10120-011-0042-4.

37. Cleeland CS, Mendoza TR, Wang XS, et al. Assessing symptom distress in cancer patients: the M.D. Anderson Symptom Inventory. Cancer, 2000; 89:1634-46. DOI: 10.1002/10970142(20001001)89:7\%3C1634::AIDCNCR29\%3E3.CO;2-V.

38. Mystakidou K, Cleeland C, Tsilika E, et al. Greek M.D.Anderson Symptom Inventory: Validation and Utility in Cancer Patients. Oncology, 2004; 67:203210. DOI: $10.1159 / 000081318$.

39. Mystakidou K, Tsilika E, Parpa E, et al. Brief cognitive assessment of cancer patients: evaluation of the Mini-Mental State Examination (MMSE) psychometric properties. Psycho-Oncology, 2007; 16:352-357. DOI: 10.1002/pon.1090.

40. National Institute on Alcohol Abuse and Alcoholism. Alcohol Alert, 1992; No.16 PH 315. https://www.niaaa.nih.gov/

41. Khan MI, Walsh D, Brito-Dellan N. Opioid and adjuvant analgesics: compared and contrasted. Am J Hosp Palliat Care, 2011; 28:378-83. DOI: 10.1177/1049909111410298.
42. Donner B, Zenz M, Tryba M, et al. Direct conversion from oral morphine to transdermal fentanyl: A multicenter study in patients with cancer pain. Pain, 1996; 64:527-534. DOI: $10.1016 / 0304-$ 3959(95)00180-8.

43. Mercadante S, Ferrera P, Villari $\mathrm{P}$, et al. Opioid escalation in patients with cancer pain: the effect of age. J Pain Symptom Manage, 2006; 32:413-9. DOI: 10.1016/j.jpainsymman.2006515.

44. Wang XS, Fairclough DL, Liao Z, et al. Longitudinal study of the relationship between chemoradiation therapy for non-small-cell lung cancer and patient symptoms. J Clin Oncol, 2006; 24:4485-91. DOI: 10.1200/JCO.20067.1126.

45. Prigozin A, Uziely B, Musgrave CF. The relationship between symptom severity and symptom interference, education, age, marital status, and type of chemotherapy treatment in Israeli women with earlystage breast cancer. Oncol Nurs Forum, 2010; 37:E411-8. DOI: 10.1188/10.ONF.E411-E418.

46. Patanwala AE, Holmes KL, Erstad BL. Analgesic response to morphine in obese and morbidly obese patients in the emergency department. Emerg Med J, 2014; 31:139-42. DOI: 10.1136/emermed-2012202168.

47. Heiskanen T, Mätzke S, Haakana S, et al. Transdermal fentanyl in cachectic cancer patients. Pain, 2009; 144:218-22. Epub 2009 May 12. DOI: 10.1016/j.pain.2009412.

48. Klepstad P, Fladvad T, Skorpen F, et al. European Palliative Care Research Collaborative (EPCRC); European Association for Palliative Care Research Network: Influence from genetic variability on opioid use for cancer pain: a European genetic association study of 2294 cancer pain patients. Pain, 2011; 152:1139-45. DOI: 10.1016/j.pain.2011140.

49. Niv D, Kreitler S. Pain and quality of life. Pain Pract, 2001; $\quad 1: 150-161$. DOI: $10.1046 /$ j.15332500.20011016.x

50. Penny KI, Purves AM, Smith BH, et al. Relationship between the chronic pain grade and measures of physical, social and psychological well-being. Pain, 1999; 79:275-9. DOI: $\quad 10.1016 / S 0304-$ 3959(98)00166-3.

51. Smith BH, Elliott AM, Chambers WA, et al. The impact of chronic pain in the community. Fam Pract, 2001; 18:292-9. DOI: 10.1093/fampra/18.3.292.

52. Mystakidou K, Parpa E, Tsilika E, et al. The relationship of subjective sleep quality, pain, and quality of life in advanced cancer patients. Sleep, 2007; 30:737-42. DOI: 10.1093/sleep/30.6.737.

53. Gerrits MM, Oppen PV, van Marwijk HW, et al. Pain and the onset of depressive and anxiety disorders. Pain, 2014; 155:53-9. DOI: 10.1016/j.pain.2013905.

54. Van den Beuken-van Everdingen MHJ, De Rijke JM, Kessels AG, et al. Prevalence of pain in patients with cancer: a systematic review of the past 40 years. Ann Oncol, 2007; 18:1437-49. DOI: 10.1093/annonc/mdm056.

55. European Pain in Cancer Survey, European Association of Palliative Care. Half of European cancer patients have moderate to severe pain: one in 
five patients does not receive treatment. J Pain Palliat Care Pharmacother, 2007; 21:51-3. DOI: 10.1300/J354v21n04_11.

56. Muijsers RB, Wagstaff AJ. Transdermal fentanyl: an updated review of its pharmacological properties and therapeutic efficacy in chronic cancer pain control. Drugs, 2001; 61:2289-307. DOI: 10.2165/00003495200161150-00014.

57. Gourlay GK. Treatment of cancer pain with transdermal fentanyl. Lancet Oncol, 2001; 2:165-72. DOI: $10.1016 /$ S1470-2045(00)00258-8.

58. World Health Organization. 1987. Traitement de la douleur cancéreuse. Geneva, Switz. Available from: http://whqlibdoc.who.int/publications/9242544825.pd f. Accessed 5 April, 2013.

59. Vargas-Schaffer G. Is the WHO analgesic ladder still valid? Twenty-four years of experience. Can Fam Physician, 2010; 56:514-7. http://www.cfp.ca/

60. Mercadante S, Fulfaro F. Alternatives to oral opioids for cancer pain. Oncology 1999; 13:215-20. http://www.cancernetwork.com/oncology-table-ofcontents

61. Jeal W, Benfield P. Transdermal fentanyl. A review of its pharmacological properties and therapeutic efficacy in pain control. Drugs, 1997; 53:109-38. DOI: 10.2165/00003495-199753010-00011.

62. Miyazaki T, Hanaoka K, Namiki A, et al. Efficacy, safety and pharmacokinetic study of a novel fentanylcontaining matrix transdermal patch system in Japanese patients with cancer pain. Clin Drug Investig, 2008; 28:313-25. DOI: 10.2165/00044011200828050-00005.

63. Ahmedzai S, Brooks D. Transdermal fentanyl versus sustained-release oral morphine in cancer pain: preference, efficacy, and quality of life. The TTSFentanyl Comparative Trial Group. J Pain Symptom Manage, 1997; 13:254-61. DOI: 10.1016/S08853924(97)00082-1.

64. Benítez-Rosario MA, Feria M, Salinas-Martín A, et al. Opioid switching from transdermal fentanyl to oral methadone in patients with cancer pain. Cancer, 2004; 101:2866-73. DOI: 10.1002/cncr.20712.

65. Dale O, Moksnes K, Kaasa S. European Palliative Care Research Collaborative pain guidelines: opioid switching to improve analgesia or reduce side effects. A systematic review. Palliat Med, 2011; 25:494-503. DOI: $10.1177 / 0269216310384902$.

66. Mercadante S, Ferrera P, Villari P, et al. Frequency, Indications, Outcomes, and Predictive Factors of Opioid Switching in an Acute Palliative Care Unit. J Pain Symptom Manage, 2009; 37:632-41. DOI: 10.1016/j.jpainsymman.2007.1224.

67. Mystakidou K, Befon S, Tsilika E, et al. Use of TTSfentanyl as a single opioid for cancer pain relief: a safety and efficacy clinical trial in patients naive to mild or strong opioids. Oncology, 2002; 62:9-16. DOI: 10.1159/000048241.

68. Riley J, Ross JR, Rutter D, et al. A retrospective study of the association between haematological and biochemical parameters and morphine intolerance in patients with cancer pain. Palliat Med, 2004; 18:19-24. DOI: $10.1191 / 0269216304$ pm856oa.
69. Bentley JB, Borel JD, Nenad RE Jr, et al. Age and fentanyl pharmacokinetics. Anesth Analg, 1982; 61:968-71. DOI: 10.1213/00000539-19821200000002.

70. Baillie SP, Bateman DN., Coates PE et al. Age and the Pharmacokinetics of Morphine; Age and Ageing, 1989; 18:258-62; DOI: 10.1093/ageing/18.4.258.

71. Holdsworth MT, Forman WB, Killilea TA, et al. Transdermal fentanyl disposition in elderly subjects. Gerontology, 1994; 40:32-7. DOI: $10.1159 / 000213572$.

72. Thompson JP, Bower S, Liddle AM, et al. Perioperative pharmacokinetics of transdermal fentanyl in elderly and young adult patients. Br. J. Anaesth, 1998; 81:152-154. DOI: 10.1093/bja/81.2.152.

73. Hall S, Gallagher RM, Gracely E, et al. The terminal cancer patient: Effects of age, gender, and primary tumor site on opioid dose. Pain Med, 2003; 4:125-134. DOI: 10.1046/j. 1526-4637.20033020.x.

74. Buntin-Mushock C, Phillip L, Moriyama K, et al. Agedependent opioid escalation in chronic pain patients. Anesth Analg, 2005; 100:1740-5. DOI: 10.1213/01.ANE000152191.29311.9B.

75. Scott JC, Stanski DR. Decreased fentanyl and alfentanil dose requirements with age. A simultaneous pharmacokinetic and pharmacodynamic evaluation. J Pharmacol Exp Ther, 1987; 240:159-66. http://jpet.aspetjournals.org/

76. Gibson SJ, Helme RD. Age-related differences in pain perception and report. Clin Geriatr Med, 2001; 17:433-56. DOI: 10.1016/S0749-0690(05)70079-3.

77. Ingrande $\mathrm{J}$ Lemmens HJM. Dose adjustment of anaesthetics in the morbidly obese. BJA, 2010; 105:i16-i23. DOI: 10.1093/bja/aeq312.

78. Baerdemaeker, Mortier EP, Strys MMRF. Pharmacokinetics in obese patients. Contin Educ Anaesth Crit Care Pain, 2004; 4:152-5. DOI: 10.1093/bjaceaccp/mkh042.

79. Lawlor PG. The panorama of opioid-related cognitive dysfunction in patients with cancer: a critical literature appraisal. Cancer, 2002; 94:1836-53. DOI: 10.1002/cncr.10389.

80. Kurita GP, Sjøgren P, Ekholm O, et al. Prevalence and predictors of cognitive dysfunction in opioid-treated patients with cancer: a multinational study. J Clin Oncol, 2011; 29:1297-303. DOI: 10.1200/JCO.2010.32.6884.

81. Baik SW, Kim KH, Kim YC, et al. Initial dose cascade of TTS fentanyl with proper adjuvant medications in cancer pain. J Korean Med Sci, 2003; 18:733-7. DOI: 10.3346/jkms.2003.18.5.733.

82. Oken MM, Creech RH, Tormey DC, et al. Toxicity and response criteria of the Eastern Cooperative Oncology Group. Am J Clin Oncol, 1982; 5:649-55. DOI: 10.1097/00000421-198212000-00014.

83. Mystakidou K, Mendoza T, Tsilika E, et al. Greek Brief Pain Inventory: Validation and Utility in Cancer Pain. Oncology, 2001; 60:35-42. DOI: 10.1159/000055294.

84. WHO Expert Consultation. Appropriate body-mass index for Asian populations and its implications for 
policy and intervention strategies. Lancet, 2004; 363:157-63. DOI: 10.1007/s10120-011-0042-4.

85. Cleeland CS, Mendoza TR, Wang XS, et al. Assessing symptom distress in cancer patients: the M.D. Anderson Symptom Inventory. Cancer, 2000; 89:1634-46. DOI: $\quad$ 10.1002/10970142(20001001)89:7\%3C1634::AIDCNCR29\%3E3.CO;2-V.

86. Mystakidou K, Cleeland C, Tsilika E, et al. Greek M.D.Anderson Symptom Inventory: Validation and Utility in Cancer Patients. Oncology, 2004; 67:203210. DOI: $10.1159 / 000081318$.

87. Mystakidou K, Tsilika E, Parpa E, et al. Brief cognitive assessment of cancer patients: evaluation of the Mini-Mental State Examination (MMSE) psychometric properties. Psycho-Oncology, 2007; 16:352-357. DOI: 10.1002/pon.1090.

88. National Institute on Alcohol Abuse and Alcoholism. Alcohol Alert, 1992; No.16 PH 315. https://www.niaaa.nih.gov/

89. Khan MI, Walsh D, Brito-Dellan N. Opioid and adjuvant analgesics: compared and contrasted. Am J Hosp Palliat Care, 2011; 28:378-83. DOI: $10.1177 / 1049909111410298$.

90. Donner B, Zenz M, Tryba M, et al. Direct conversion from oral morphine to transdermal fentanyl: A multicenter study in patients with cancer pain. Pain, 1996; 64:527-534. DOI: $10.1016 / 0304-$ 3959(95)00180-8.

91. Mercadante S, Ferrera P, Villari P, et al. Opioid escalation in patients with cancer pain: the effect of age. J Pain Symptom Manage, 2006; 32:413-9. DOI: 10.1016/j.jpainsymman.2006515.

92. Wang XS, Fairclough DL, Liao Z, et al. Longitudinal study of the relationship between chemoradiation therapy for non-small-cell lung cancer and patient symptoms. J Clin Oncol, 2006; 24:4485-91. DOI: 10.1200/JCO.20067.1126.

93. Prigozin A, Uziely B, Musgrave CF. The relationship between symptom severity and symptom interference, education, age, marital status, and type of chemotherapy treatment in Israeli women with earlystage breast cancer. Oncol Nurs Forum, 2010; 37:E411-8. DOI: 10.1188/10.ONF.E411-E418.

94. Patanwala AE, Holmes KL, Erstad BL. Analgesic response to morphine in obese and morbidly obese patients in the emergency department. Emerg Med J, 2014; 31:139-42. DOI: 10.1136/emermed-2012202168 .

95. Heiskanen T, Mätzke S, Haakana S, et al. Transdermal fentanyl in cachectic cancer patients. Pain, 2009; 144:218-22. Epub 2009 May 12. DOI: 10.1016/j.pain.2009412.

96. Klepstad P, Fladvad T, Skorpen F, et al. European Palliative Care Research Collaborative (EPCRC); European Association for Palliative Care Research Network: Influence from genetic variability on opioid use for cancer pain: a European genetic association study of 2294 cancer pain patients. Pain, 2011; 152:1139-45. DOI: 10.1016/j.pain.2011140. 